\title{
Spinal Mobility, Vertebral Squaring, Pulmonary Function, Pain, Fatigue, and Quality of Life in Patients With Ankylosing Spondylitis
}

\author{
Hyungpil Cho, $\mathrm{MD}^{1}$, Taikon Kim, $\mathrm{MD}^{1}$, Tae-Hwan Kim, $\mathrm{MD}^{2}$, Seunghun Lee, $\mathrm{MD}^{3}$, Kyu Hoon Lee, $\mathrm{MD}^{1}$
}

\begin{abstract}
${ }^{1}$ Department of Rehabilitation Medicine, Hanyang University Medical Center, Hanyang University College of Medicine, Seoul; ${ }^{2}$ Department of Rheumatology, Hospital for Rheumatic Diseases, Hanyang University College of Medicine, Seoul; ${ }^{3}$ Department of Radiology, Hanyang University Medical Center, Hanyang University College of Medicine, Seoul, Korea
\end{abstract}

\begin{abstract}
Objective To investigate the relationships between spinal mobility, pulmonary function, structural change of the spine, pain, fatigue, and quality of life (QOL) in patients with ankylosing spondylitis (AS).

Methods Thirty-six patients with AS were recruited. Their spinal mobility was examined through seven physical tests: modified Schober test, lateral bending, chest expansion, occiput to wall, finger to ground, bimalleolar distance, and range of motion (ROM) of the spine. Pulmonary Function Test (PFT) was performed using a spirometer, and vertebral squaring was evaluated through the modified Stoke Ankylosing Spondylitis Spinal Score (mSASSS). QOL, disease activity, functional capacity, and fatigue were evaluated by SF-36 Health Survey (SF-36), the Bath Ankylosing Spondylitis Disease Activity Index (BASDAI), the Bath Ankylosing Spondylitis Functional Index (BASFI), and the Multidimensional Assessment of Fatigue (MAF) scale, respectively. Perceived physical condition and degree of pain were assessed using $10 \mathrm{~cm}$ visual analogue scale.

Results Participants showed reduced spinal mobility, which was negatively correlated with mSASSS. PFT results showed reduced forced expiratory volume in one second (FEV1) and forced vital capacity (FVC) and increased FEV1/FVC. Reduced FEV1 and FVC showed positive correlations with reduced spinal mobility and a negative relationship with mSASSS. Perceived physical condition and degree of pain were both significantly related to the SF-36, BASDAI, BASFI, and MAF scores.

Conclusion This study shows that both reduced spinal mobility and radiographic changes in the vertebral body may have a predictive value for pulmonary impairment in patients with AS. Likewise, pain and perceived physical condition may play an important role in the QOL, functional capacity, and fatigue level of these patients.
\end{abstract}

Keywords Ankylosing spondylitis, Joint range of motion, Pulmonary function tests, Quality of life

Department of Rehabilitation Medicine, Hanyang University Medical Center, Hanyang University College of Medicine, 222 Wangsimni-ro, Seongdonggu, Seoul 133-791, Korea

Tel: +82-2-2290-9349, Fax: +82-2-2282-0772, E-mail: dumitru1@hanyang.ac.kr

(c) This is an open-access article distributed under the terms of the Creative Commons Attribution Non-Commercial License (http://creativecommons.org/ licenses/by-nc/3.0) which permits unrestricted noncommercial use, distribution, and reproduction in any medium, provided the original work is properly cited. Copyright $\odot 2013$ by Korean Academy of Rehabilitation Medicine 


\section{INTRODUCTION}

Ankylosing spondylitis (AS) is a chronic inflammatory disease with progressive features, the primary affecting sites of which are the joints of the pelvis and the axial skeleton [1]. It has been reported that AS affects approximately $0.1 \%$ of the population [2]. In addition, AS may affect peripheral joints, the skin, eyes, or bowel, and also increase the risk of cardiovascular or pulmonary manifestation [3]. The reduced spinal mobility that occurs in the disease is the result of the progressive ossification and fusion of the vertebral joints caused by inflammation [4].

To evaluate structural changes to the vertebrae in AS, the modified Stoke Ankylosing Spondylitis Spine Score (mSASSS) is commonly used. This assesses the anterior corners of the cervical and lumbar vertebra. Several reports have suggested that the structural damage of the spine presented in radiographic findings is associated with impaired spinal mobility [5-9]. However, controversy exists in the literature regarding the relationship between spinal radiographic findings and spinal mobility [6,8-11].

Some previous research has suggested that impairment of spinal mobility, along with chest wall immobility, may be one of the factors that cause pulmonary dysfunction in AS [4,12-14], although other researchers have reported that the primary target of pulmonary manifestation in AS may be lung parenchyma $[15,16]$. Pain and stiffness caused by inflammation in the spine, as well as immobility of the chest wall and the spine, may also contribute to the decline of pulmonary function in this patient group $[12,13,17]$.

Fatigue presents as a feeling of exhaustion and a lack of energy with reduced capacity and efficiency in work [1820]. More than $50 \%$ of patients with AS complain of fatigue $[21,22]$, and the condition has been suggested to be linked to disease activity, functional level, pain, stiffness, mood, and occupational capability [18,22-24]. However, the clinical impact of the aforementioned factors on fatigue in this population remains unclear.

Quality of life (QOL) is an important outcome in patients with chronic disease. There have been a few reports related to QOL in patients with AS [25], with a recent report revealing an association between spinal mobility and QOL in patients with AS [26].

In light of the relative scarcity of research in this area, the aim of the current study was to assess spinal mobility, radiographic changes in the spine, pulmonary function, pain, fatigue, and QOL in patient with AS, and to reveal the relationship between these variables.

\section{MATERIALS AND METHODS}

Thirty-six adult patients with AS were recruited from the outpatient department. All participants were outpatients diagnosed using the modified New York criteria [27]. The exclusion criteria were: 1) other musculoskeletal problems in the spine or thoracic cage, 2) cardiopulmonary disease, and 3) a concurrent medical condition that could be reasonably expected to affect the patient's functional level or QOL.

The SF-36 Health Survey (SF-36) was employed to evaluate the QOL of participants. This measure consists of 36 items, and answers are scored and summed to produce a value from 0 to 100 for each of the eight domains (physical functioning, role-physical, bodily pain, general health, vitality, social functioning, role-emotional, and mental health) as well as to give an overall score [28]. The Bath Ankylosing Spondylitis Disease Activity Index (BASDAI), the Bath Ankylosing Spondylitis Functional Index (BASFI), and the Multidimensional Assessment of Fatigue (MAF) scale were used to assess participants' disease activity, functional impairment and degree of fatigue, respectively. The BASDAI has six questions related to fatigue, back pain, peripheral pain, peripheral swelling, local tenderness, and morning stiffness (severity and duration). Other than the item relating to morning stiffness, all questions are scored from 0 (none) to 10 (very severe) using a visual analogue scale (VAS). The average of the first five questions becomes the final score, with a higher score indicating more severe disease activity [2931]. The BASFI is comprised of ten questions assessing functional limitations and the level of physical activity at home and work. VAS is used to score each question from 0 (easy) to 10 (impossible), and the average value over the 10 questions is the BASFI score [32]. The MAF assess the degree of fatigue by employing 16 items using a Numeric Rating Scale, and scores for 15 items are transformed into a score from 0 (no fatigue) to 50 (severe fatigue) [33-35]. Participants' perceived physical condition and degree of pain (pain in any joint, back pain, and nocturnal back pain) during the last week were assessed by using a $10 \mathrm{~cm}$ 
VAS. We also collected participants' general characteristics including their sex, age, weight, height, and the date of onset and diagnosis. All questionnaires were given to participants with detailed instructions and demonstrations and were returned to us by mail.

Participants' spinal mobility was also examined through seven physical tests: 1) modified Schober test, 2) lateral bending, 3) chest expansion, 4) occiput to wall, 5) finger to ground, 6) bimalleolar distance, and 7) the range of motion (ROM) for the cervical and thoracolumbar spine, as measured by inclinometer. Vertebral squaring was also evaluated through the mSASSS of the cervical and lumbar spine. Plain radiographs of the cervical and lumbar spine were obtained, and the anterior angles of the cervical vertebra (lower C2 to upper T1) and lumbar vertebra (lower T12 to upper S1) were scored. Each anterior vertebral angle was scored at 0 (normal), 1 (erosion, squaring, or

Table 1. Demographic characteristics, spinal mobility, pulmonary function, and mSASSS of participants

\begin{tabular}{lcc}
\hline \multicolumn{1}{c}{ Variable } & Value \\
\hline Age $(\mathrm{yr})$ & $34.5 \pm 9.8$ \\
\hline Duration from onset & $11.3 \pm 8.6$ \\
\hline Height $(\mathrm{m})$ & $1.7 \pm 0.1$ \\
\hline Weight $(\mathrm{kg})$ & $67.0 \pm 11.5$ \\
\hline BMI $\left(\mathrm{kg} / \mathrm{m}^{2}\right)$ & $23.0 \pm 3.5$ \\
\hline Modified Schober $(\mathrm{cm})$ & $18.0 \pm 2.6$ \\
\hline Lateral bending $(\mathrm{cm})$ & $53.3 \pm 7.6$ \\
\hline Chest expansion $(\mathrm{cm})$ & $3.4 \pm 1.4$ \\
\hline Occiput to wall $(\mathrm{cm})$ & $7.0 \pm 25.7$ \\
\hline Finger to ground $(\mathrm{cm})$ & $23.1 \pm 21.0$ \\
\hline Bimalleolar distance $(\mathrm{cm})$ & $104.8 \pm 29.1$ \\
\hline ROM of C and T-L spine $\left({ }^{\circ}\right)$ & $365.6 \pm 202.8$ \\
\hline FEV1 $(\mathrm{L})$ & $3.1 \pm 0.7$ \\
\hline FEV1 $(\%$ of predicted value) & $85.0 \pm 13.7$ \\
\hline FVC (L) & $3.3 \pm 0.8$ \\
\hline FVC $(\%$ of predicted value) & $80.2 \pm 15.4$ \\
\hline FEV1/FVC & $93.1 \pm 6.3$ \\
\hline FEV1/FVC (\% of predicted value) & $109.1 \pm 11.3$ \\
\hline mSASSS & $21.4 \pm 22.0$ \\
\hline
\end{tabular}

Values are presented as mean \pm standard deviation.

BMI, body mass index; ROM, range of motion; $\mathrm{C}$ and T-L spine, cervical and thoracolumbar spine; FEV1, forced expiratory volume in one second; FVC, forced vital capacity; mSASSS, modified Stoke Ankylosing Spondylitis Spinal Score. sclerosis), 2 (syndesmophyte) or 3 (bridging), with total scores ranging from 0 to 72 [36]. The mSASSS was scored by a musculoskeletal radiologist. Pulmonary Function Test (PFT) was performed using a MicroPlus Spirometer (CareFusion Corporation, San Diego, CA, USA), and the forced expiratory volume in one second (FEV1), forced vital capacity (FVC) and FEV1/FVC values were obtained. The PFT was performed three times for each participant, so that the best result could be obtained.

The Spearman coefficient was used to see the correlation among variables. A p-value of less than 0.05 was considered to be significant in all analyses. Data analyses were performed using SPSS ver. 17.0 (SPSS Inc., Chicago, IL, USA) for Windows.

\section{RESULTS}

Of thirty-six participants, thirty-one were males (86.1\%) and five were females (13.9\%). Their mean age was $34.5 \pm 9.8$ years (ranging from 24 to 52 years) and

Table 2. Variables related to quality of life, disease activity, functional level, fatigue, and pain $(\mathrm{n}=26)$

\begin{tabular}{|lc|}
\hline \multicolumn{1}{c}{ Variable } & Value \\
\hline Age (yr) & $34.7 \pm 9.7$ \\
\hline SF-36 Health Survey & \\
\hline Physical functioning & $52.3 \pm 28.7$ \\
\hline Role-physical & $22.1 \pm 35.6$ \\
\hline Bodily pain & $42.2 \pm 28.4$ \\
\hline General health & $37.7 \pm 18.4$ \\
\hline Vitality & $40.2 \pm 23.9$ \\
\hline Social functioning & $51.4 \pm 13.8$ \\
\hline Role-emotional & $29.5 \pm 40.4$ \\
\hline Mental health & $42.3 \pm 18.8$ \\
\hline Total & $39.7 \pm 16.2$ \\
\hline BASDAI & $4.6 \pm 2.2$ \\
\hline BASFI & $4.2 \pm 3.0$ \\
\hline MAF & $27.36 \pm 8.1$ \\
\hline Perceptive physical condition & $5.2 \pm 2.9$ \\
\hline Pain in any joint (recent 1 wk) & $5.6 \pm 3.1$ \\
\hline Back pain (recent 1 wk) & $5.0 \pm 3.0$ \\
\hline Nocturnal back pain (recent 1 wk) & $4.4 \pm 2.8$ \\
\hline
\end{tabular}

Values are presented as mean \pm standard deviation. BASDAI, Bath Ankylosing Spondylitis Disease Activity Index; BASFI, Bath Ankylosing Spondylitis Functional Index; MAF, Multidimensional Assessment of Fatigue. 
the mean duration from the onset was $11.3 \pm 8.6$ years (ranging from 0.1 to 26 years). They showed reduced spinal mobility in physical examination, and their mean combined ROM of the cervical and the thoracolumbar spines was $365.6^{\circ} \pm 202.8^{\circ}$ (Table 1 ). The mean mSASSS of participants was $21.4 \pm 22.0$. When we analyzed their PFT results, a restrictive pattern was revealed with reduced FEV1 $(85.0 \% \pm 13.7 \%$ of predicted value) and FVC $(80.2 \% \pm 15.4 \%$ of predicted value) and increased FEV1/ FVC $(109.1 \% \pm 11.3 \%$ of predicted value) (Table 1$)$. Only twenty-six participants replied to the questionnaire items, including SF-36, BASDAI, BASFI, and MAF, and their mean age and duration from onset were $34.7 \pm 9.7$ and $13.2 \pm 8.8$ years, respectively. Their QOL, disease activity, functional level, fatigue, and pain are described in Table 2.

Relationship between spinal mobility and structural changes of the spine

The mSASSS score was negatively correlated with modified Schober test, chest expansion, and ROM of the spine, whereas it was positively correlated with lateral bending. Other physical examination results did not show any significant correlations with mSASSS. The ROM of the spine showed its strongest relationship with mSASSS (coefficient, -0.747; $\mathrm{p}<0.001$ ) (Table 3).

Pulmonary function: the relationships with spinal mobility and structural changes of the spine

Both FEV1 and FVC showed positive correlations with modified Schober test, chest expansion, bimalleolar dis-

Table 3. Correlation between mSASSS and spinal mobility

\begin{tabular}{lcc}
\hline \multicolumn{1}{c}{ Variable } & Coefficient $^{\text {a) }}$ & p-value \\
\hline Modified Schober & -0.579 & 0.001 \\
Lateral bending & 0.584 & $<0.001$ \\
Chest expansion & -0.475 & 0.003 \\
Occiput to wall & -0.037 & 0.834 \\
Finger to ground & 0.211 & 0.216 \\
Bimalleolar distance & -0.251 & 0.145 \\
\hline ROM of C and T-L spine & -0.747 & $<0.001$ \\
\hline
\end{tabular}

mSASSS, Modified Stoke Ankylosing Spondylitis Spinal Score; ROM, range of motion; C and T-L spine, cervical and thoracolumbar spine.

${ }^{\text {a)}}$ Spearman correlation coefficient. tance, and ROM of the spine and showed negative correlations with finger to ground. FEV1 was also negatively correlated with mSASSS (coefficient, $-0.448 ; \mathrm{p}<0.01$ ). There was also a negative correlation between FVC and mSASSS, but this was not statistically correlated (coefficient, -0.324; $\mathrm{p}=0.06$ ). However, all variables related to spinal mobility or mSASSS were not correlated with FEV1/FVC. The body mass index did not show any significant correlations with FEV1, FVC, or FEV1/FVC (Table 4).

The relationships among $\mathrm{OOL}$, disease activity, functional level, fatigue, and pain

MAF had a negative correlation with SF-36 and positive correlations with BASDAI and BASFI (Table 5). Perceived physical condition, pain in any joint, and back pain were all negatively correlated with SF-36, whereas they were positively correlated with BASDAI, BASFI, and MAF. Nocturnal back pain also showed a negative correlation with SF-36 and a positive correlation with BASDAI and BASFI. However, the correlations between nocturnal back pain and MAF were not statistically significant (coefficient, 0.363; $\mathrm{p}=0.068$ ) (Table 5).

OOL, disease activity, functional level, fatigue, and pain: the relationships with other variables

BASFI was positively correlated with finger to ground

Table 4. Correlation between PFT and other variables (unit, \% of prediction)

\begin{tabular}{lccc}
\hline \multicolumn{1}{c}{ Variable } & FEV1 & FVC & FEV1/FVC \\
\hline Modified Schober & $0.408^{* *}$ & $0.428^{*}$ & -0.234 \\
Lateral bending & -0.142 & -0.115 & 0.031 \\
Chest expansion & $0.476^{* *}$ & $0.378^{*}$ & -0.051 \\
Occiput to wall & 0.130 & 0.030 & 0.147 \\
Finger to ground & $-0.469^{* *}$ & $-0.412^{*}$ & 0.085 \\
Bimalleolar distance & $0.615^{* *}$ & $0.652^{* *}$ & -0.251 \\
ROM of C and T-L spine & $0.537^{* *}$ & $0.498^{* *}$ & -0.196 \\
mSASSS & $-0.448^{* *}$ & -0.324 & 0.008 \\
BMI & 0.086 & 0.149 & -0.120 \\
\hline
\end{tabular}

Spearman correlation coefficients.

FEV1, forced expiratory volume in one second; FVC, forced vital capacity; ROM, range of motion; C and T-L spine, cervical and thoracolumbar spine; mSASSS, modified Stoke Ankylosing Spondylitis Spinal Score; BMI, body mass index. ${ }^{*} \mathrm{p}<0.05,{ }^{* *} \mathrm{p}<0.01$. 
Table 5. Quality of life, disease activity, functional level, fatigue, and perceived physical condition and pain: the relationship to other variables

\begin{tabular}{lcccccccc}
\hline \multicolumn{1}{c}{ Variable } & SF-36 & BASDAI & BASFI & MAF & $\begin{array}{c}\text { Physical } \\
\text { condition }^{\text {a) }}\end{array}$ & $\begin{array}{c}\text { Pain in } \\
\text { any joint }^{\text {a) }}\end{array}$ & $\begin{array}{c}\text { Back } \\
\text { pain }^{\text {a) }}\end{array}$ & $\begin{array}{c}\text { Nocturnal } \\
\text { back pain }^{\text {a) }}\end{array}$ \\
\hline SF-36 & - & - & - & - & $-0.702^{* *}$ & $-0.660^{* *}$ & $-0.776^{* *}$ & $-0.681^{* *}$ \\
BASDAI & $-0.755^{* *}$ & - & - & - & $0.793^{* *}$ & $0.770^{* *}$ & $0.748^{* *}$ & $0.691^{* *}$ \\
\hline BASFI & $-0.660^{* *}$ & $0.651^{* *}$ & - & - & $0.694^{* *}$ & $0.832^{* *}$ & $0.766^{* *}$ & $0.557^{* *}$ \\
\hline MAF & $-0.558^{* *}$ & $0.538^{* *}$ & $0.433^{*}$ & - & $0.470^{* *}$ & $0.426^{*}$ & $0.445^{*}$ & 0.363 \\
\hline Modified Schober & 0.352 & -0.384 & $-0.432^{*}$ & -0.151 & -0.341 & -0.343 & -0.375 & -0.336 \\
\hline Lateral bending & -0.124 & 0.121 & 0.260 & 0.171 & 0.150 & -0.003 & 0.196 & 0.134 \\
\hline Chest expansion & 0.038 & -0.187 & -0.075 & 0.051 & -0.022 & -0.082 & -0.083 & -0.158 \\
\hline Occiput to wall & -0.122 & -0.009 & 0.369 & 0.211 & 0.165 & 0.081 & 0.021 & 0.109 \\
\hline Finger to ground & -0.173 & 0.168 & $0.500^{* *}$ & 0.132 & 0.169 & 0.245 & 0.315 & 0.194 \\
Bimalleolar distance & 0.341 & $-0.542^{* *}$ & $-0.552^{* *}$ & -0.113 & $-0.466^{* *}$ & -0.337 & -0.279 & -0.262 \\
\hline ROM, C and T-L spine & 0.282 & -0.135 & -0.364 & -0.013 & -0.213 & -0.083 & -0.184 & -0.030 \\
mSASSS & -0.117 & -0.036 & 0.162 & -0.003 & 0.044 & 0.006 & -0.028 & -0.049 \\
\hline FEV1 & 0.094 & 0.019 & -0.244 & 0.091 & -0.045 & -0.077 & -0.158 & -0.057 \\
\hline FVC & 0.158 & -0.198 & -0.310 & -0.045 & -0.236 & -0.251 & -0.253 & -0.229 \\
\hline FEV1/FVC & -0.184 & $0.417^{*}$ & 0.224 & 0.311 & $0.444^{*}$ & $0.411^{*}$ & 0.299 & $0.414^{*}$ \\
\hline BMI & 0.114 & -0.149 & -0.139 & 0.274 & -0.149 & -0.116 & -0.229 & -0.092 \\
\hline
\end{tabular}

Spearman correlation coefficients.

SF-36, SF-36 Health Survey; BASDAI, Bath Ankylosing Spondylitis Disease Activity Index; BASFI, Bath Ankylosing Spondylitis Functional Index; MAF, Multidimentional Assessment Of Fatigue; ROM, range of motion; C and T-L spine, cervical and thoracolumbar spine; mSASSS, modified Stoke Ankylosing Spondylitis Spinal Score; FEV1, forced expiratory volume in one second; FVC, forced vital capacity; BMI, body mass index.

${ }^{a)}$ Level of perceived physical condition or severity of pain over 1 week, using numeric scales from 0 (the best condition or no pain) to 10 (the worst condition or the most severe pain possible). ${ }^{*} \mathrm{p}<0.05,{ }^{* *} \mathrm{p}<0.01$.

and negatively correlated with modified Schober test and the bimalleolar distance. There was also a negative correlation between BASDAI and the bimalleolar distance. However SF-36, BASDAI, BASFI, and MAF did not show any consistent relationships with modified Schober test, lateral bending, chest expansion, occiput to wall, finger to ground, bimalleolar distance, or ROM of the spine (Table 5). SF-36, BASFI, and MAF were not significantly correlated with pulmonary function, and only BASDAI showed a positive correlation with FEV1/FVC (coefficient, 0.417; $\mathrm{p}=0.038$ ) (Table 5). Perceived physical condition, pain in any joint, and nocturnal back pain were all positively correlated with FEV1/FVC, but there were no other correlations found between the patient's perceived physical condition and pain and other variables, including ROM, mSASSS, FEV1 and FVC (Table 5).

\section{DISCUSSION}

This study was conducted in patients with AS to evaluate their spinal mobility, the spinal radiographic findings, pulmonary function, QOL, pain and fatigue, and to assess the relationships among these outcomes. Previous research has shown inconsistent results for the relationship between the radiographic findings and spinal mobility [5-10]. Our results suggest that more severe radiographic changes in the spine are related with reduced spinal mobility and chest wall motion, which was confirmed in the ROM of the spine as assessed by inclinometer and the results of three physical examinations (modified Schober, lateral bending, and chest expansion tests).

The pulmonary function of patients with AS is known to show a restrictive pattern caused by stiffness and interstitial lung disease [13,15,37-39], and patients in this study also showed some restrictive patterns in PFT with increased FEV1/FVC and reduced lung capacity. Reduced 
FEV1 was another result indicated by our study. These findings may reinforce previous reports that there is small airway involvement in the reduced volumic airway conductance seen in patient with AS $[13,15]$. Both reduced FEV1 and FVC were related to reduced spinal mobility and spinal radiographic changes. This result implies that spinal mobility assessment, as well as radiographic changes in the vertebral body, may have a predictive value for the respiratory vital capacity of patients with AS, and this finding can be applied to predict pulmonary function and to provide appropriate rehabilitative interventions in clinical settings. However, FEV1/FVC showed no relationship with either spinal mobility or radiographic changes, which may be explained by the fact that both FEV1 and FVC were reduced simultaneously.

This study also shows that there are significant relationships among decreased QOL, more severe disease activity, greater impairments in functionality and a higher degree of fatigue, results which correspond with the findings of earlier study [25].

Previous research has reported that pulmonary impairments can reduce exercise capacity [40], and may also affect functional level and QOL [38]. Spinal mobility is also known to impair the QOL in patients with AS $[26,37]$. However, our study revealed that QOL and functional level were not related to spinal mobility, radiographic changes in the spine or PFT. This result may be related to reports that cardiopulmonary fitness is more important than is spinal mobility, chest expansion or lung capacity. Fisher et al. [4] reported that patients with AS may maintain an adequate work capacity by carrying out regular exercise with modest intensity, irrespective of spinal or chest wall immobility with reduced vital capacity. Another study has revealed that the functional capacity of patients with AS was not significantly influenced by spinal and chest wall immobility with a restrictive pulmonary pattern, as confirmed by PFT, and emphasized the role of moderate physical activity within an active lifestyle for maintaining exercise tolerance [14]. In this study, poorer perceived physical condition and more severe pain were significantly related with decreased QOL, more severe disease activity, greater impairments to functionality, and a higher degree of fatigue. This result implies that pain and perceived physical condition may both have an important role in QOL, functional capacity, and fatigue in patients with AS, although we should take into account that both the BASDAI and SF-36 include items related to pain and physical condition. That said, the results suggest that we may need to focus on pain management and encouraging AS patients to maintain good physical activity levels, in addition to improving spinal mobility or preventing structural changes of the spine.

This study has a limitation in that it was a crosssectional study, and as such extended study in a larger population with a long-term follow-up will be required to confirm the relationship between the changes of each parameter assessed in this study. Considering additional parameters such as the maximum oxygen capacity would also be helpful in clarifying the role of cardiopulmonary fitness in this model.

In conclusion, this study shows that both spinal mobility and radiographic changes in the vertebral body may have a predictive value for pulmonary impairment in patients with AS, and can be applied to predict pulmonary function in clinical settings. We also suggest that providing appropriate pain management and recommending the maintenance of a good physical activity level may be important in improving the QOL and functional capability of patients with AS.

\section{CONFLICT OF INTEREST}

No potential conflict of interest relevant to this article was reported.

\section{REFERENCES}

1. Braun J, Sieper J. Ankylosing spondylitis. Lancet 2007;369:1379-90.

2. Calin A, Fries JF. Striking prevalence of ankylosing spondylitis in "healthy" w27 positive males and females. N Engl J Med 1975;293:835-9.

3. Heeneman S, Daemen MJ. Cardiovascular risks in spondyloarthritides. Curr Opin Rheumatol 2007;19:358-62.

4. Fisher LR, Cawley MI, Holgate ST. Relation between chest expansion, pulmonary function, and exercise tolerance in patients with ankylosing spondylitis. Ann Rheum Dis 1990;49:921-5.

5. Kaya T, Gelal F, Gunaydin R. The relationship between severity and extent of spinal involvement and spinal mobility and physical functioning in patients with an- 
kylosing spondylitis. Clin Rheumatol 2006;25:835-9.

6. Kennedy LG, Jenkinson TR, Mallorie PA, Whitelock HC, Garrett SL, Calin A. Ankylosing spondylitis: the correlation between a new metrology score and radiology. Br J Rheumatol 1995;34:767-70.

7. Viitanen JV, Heikkila S, Kokko ML, Kautiainen H. Clinical assessment of spinal mobility measurements in ankylosing spondylitis: a compact set for follow-up and trials? Clin Rheumatol 2000;19:131-7.

8. Viitanen JV, Kokko ML, Lehtinen K, Suni J, Kautiainen H. Correlation between mobility restrictions and radiologic changes in ankylosing spondylitis. Spine (Phila Pa 1976) 1995;20:492-6.

9. Wanders A, Landewe R, Dougados M, Mielants H, van der Linden S, van der Heijde D. Association between radiographic damage of the spine and spinal mobility for individual patients with ankylosing spondylitis: can assessment of spinal mobility be a proxy for radiographic evaluation? Ann Rheum Dis 2005;64:98894.

10. Viitanen JV, Kokko ML, Heikkila S, Kautiainen H. Neck mobility assessment in ankylosing spondylitis: a clinical study of nine measurements including new tape methods for cervical rotation and lateral flexion. $\mathrm{Br} \mathrm{J}$ Rheumatol 1998;37:377-81.

11. Spoorenberg A, van der Heijde D, de Klerk E, Dougados M, de Vlam K, Mielants H, et al. Relative value of erythrocyte sedimentation rate and C-reactive protein in assessment of disease activity in ankylosing spondylitis. J Rheumatol 1999;26:980-4.

12. Donath J, Miller A. Restrictive chest wall disorders. Semin Respir Crit Care Med 2009;30:275-92.

13. Feltelius N, Hedenstrom H, Hillerdal G, Hallgren R. Pulmonary involvement in ankylosing spondylitis. Ann Rheum Dis 1986;45:736-40.

14. Seçkin U, Bolukbasi N, Gursel G, Eroz S, Sepici V, Ekim N. Relationship between pulmonary function and exercise tolerance in patients with ankylosing spondylitis. Clin Exp Rheumatol 2000;18:503-6.

15. Altin R, Ozdolap S, Savranlar A, Sarikaya S, Tor M, Kart L, et al. Comparison of early and late pleuropulmonary findings of ankylosing spondylitis by highresolution computed tomography and effects on patients' daily life. Clin Rheumatol 2005;24:22-8.

16. Baser S, Cubukcu S, Ozkurt S, Sabir N, Akdag B, Diri E. Pulmonary involvement starts in early stage ankylos- ing spondylitis. Scand J Rheumatol 2006;35:325-7.

17. El Maghraoui A. Pleuropulmonary involvement in ankylosing spondylitis. Joint Bone Spine 2005;72:496502.

18. Ibn Yacoub Y, Amine B, Laatiris A, Abouqal R, HajjajHassouni N. Assessment of fatigue in Moroccan patients with ankylosing spondylitis. Clin Rheumatol 2010;29:1295-9.

19. Krupp LB, Pollina DA. Mechanisms and management of fatigue in progressive neurological disorders. Curr Opin Neurol 1996;9:456-60.

20. Swain MG. Fatigue in chronic disease. Clin Sci (Lond) 2000;99:1-8.

21. Calin A, Edmunds L, Kennedy LG. Fatigue in ankylosing spondylitis: why is it ignored? J Rheumatol 1993;20:991-5.

22. Jones SD, Koh WH, Steiner A, Garrett SL, Calin A. Fatigue in ankylosing spondylitis: its prevalence and relationship to disease activity, sleep, and other factors. J Rheumatol 1996;23:487-90.

23. Dagfinrud H, Vollestad NK, Loge JH, Kvien TK, Mengshoel AM. Fatigue in patients with ankylosing spondylitis: a comparison with the general population and associations with clinical and self-reported measures. Arthritis Rheum 2005;53:5-11.

24. van Tubergen A, Coenen J, Landewe R, Spoorenberg A, Chorus A, Boonen A, et al. Assessment of fatigue in patients with ankylosing spondylitis: a psychometric analysis. Arthritis Rheum 2002;47:8-16.

25. Bodur H, Ataman S, Rezvani A, Bugdayci DS, Cevik R, Birtane $\mathrm{M}$, et al. Quality of life and related variables in patients with ankylosing spondylitis. Qual Life Res 2011;20:543-9.

26. Vesovic-Potic V, Mustur D, Stanisavljevic D, Ille T, Ille M. Relationship between spinal mobility measures and quality of life in patients with ankylosing spondylitis. Rheumatol Int 2009;29:879-84.

27. van der Linden S, Valkenburg HA, Cats A. Evaluation of diagnostic criteria for ankylosing spondylitis: a proposal for modification of the New York criteria. Arthritis Rheum 1984;27:361-8.

28. Ware JE, Kosinski M, Dewey JE, Gandek B. SF-36 health survey: manual and interpretation guide. Lincoln: Quality Metric Inc.; 2000.

29. Wei JC, Wong RH, Huang JH, Yu CT, Chou CT, Jan MS, et al. Evaluation of internal consistency and re-test 
reliability of Bath ankylosing spondylitis indices in a large cohort of adult and juvenile spondylitis patients in Taiwan. Clin Rheumatol 2007;26:1685-91.

30. Calin A, Nakache JP, Gueguen A, Zeidler H, Mielants $\mathrm{H}$, Dougados M. Defining disease activity in ankylosing spondylitis: is a combination of variables (Bath Ankylosing Spondylitis Disease Activity Index) an appropriate instrument? Rheumatology (Oxford) 1999;38:878-82.

31. Garrett S, Jenkinson T, Kennedy LG, Whitelock H, Gaisford P, Calin A. A new approach to defining disease status in ankylosing spondylitis: the Bath Ankylosing Spondylitis Disease Activity Index. J Rheumatol 1994;21:2286-91.

32. Calin A, Garrett S, Whitelock H, Kennedy LG, O'Hea J, Mallorie P, et al. A new approach to defining functional ability in ankylosing spondylitis: the development of the Bath Ankylosing Spondylitis Functional Index. J Rheumatol 1994;21:2281-5.

33. Belza BL, Henke CJ, Yelin EH, Epstein WV, Gilliss CL. Correlates of fatigue in older adults with rheumatoid arthritis. Nurs Res 1993;42:93-9.

34. Belza BL. Comparison of self-reported fatigue in rheumatoid arthritis and controls. J Rheumatol 1995;22:639-43.

35. Aissaoui N, Rostom S, Hakkou J, Berrada Ghziouel K, Bahiri R, Abouqal R, et al. Fatigue in patients with ankylosing spondylitis: prevalence and relationships with disease-specific variables, psychological status, and sleep disturbance. Rheumatol Int 2012;32:211724.

36. Creemers MC, Franssen MJ, van't Hof MA, Gribnau FW, van de Putte LB, van Riel PL. Assessment of outcome in ankylosing spondylitis: an extended radiographic scoring system. Ann Rheum Dis 2005;64:1279.

37. Berdal G, Halvorsen S, van der Heijde D, Mowe M, Dagfinrud H. Restrictive pulmonary function is more prevalent in patients with ankylosing spondylitis than in matched population controls and is associated with impaired spinal mobility: a comparative study. Arthritis Res Ther 2012;14:R19.

38. Dincer U, Cakar E, Kiralp MZ, Bozkanat E, Kilac H, Dursun $\mathrm{H}$. The pulmonary involvement in rheumatic diseases: pulmonary effects of ankylosing spondylitis and its impact on functionality and quality of life. Tohoku J Exp Med 2007;212:423-30.

39. Solak O, Fidan F, Dundar U, Turel A, Aycicek A, Kavuncu V, et al. The prevalence of obstructive sleep apnoea syndrome in ankylosing spondylitis patients. Rheumatology (Oxford) 2009;48:433-5.

40. Ozdem Yr O, Inanici F, Hascelik Z. Reduced vital capacity leads to exercise intolerance in patients with ankylosing spondylitis. Eur J Phys Rehabil Med 2011;47:391-7. 